\title{
ENTREVISTA COM JOCA REINERS TERRON
}

André Cardoso (UFF)

Pedro Sasse (UFF)

Recebido em 08 mai 2020. André Cardoso é Professor associado de Literaturas de Aprovado em 23 mai 2020. Língua Inglesa na Universidade Federal Fluminense (UFF).

Pedro Sasse é Doutor em Estudos de Literatura pela Universidade Federal Fluminense na área de Literatura, História e Cultura, coordenador do Grupo de Estudos "Escritos Suspeitos" (UFF) e membro dos grupos de pesquisas "Estudos do Gótico" (CNPq) e "Interferências: literatura e ciência". Possui experiência na área de Teoria Literária e Literatura Comparada, com ênfase em: literatura criminal, literatura distópica, gótico, violência urbana, terror. 


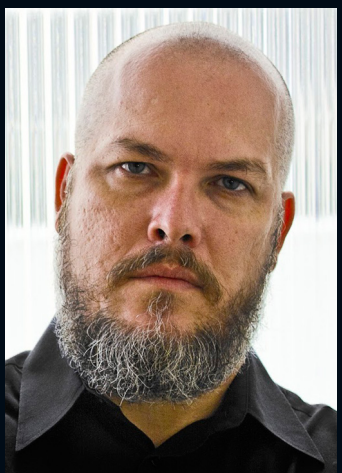

Joca Reiners Terron é escritor, editor e designer gráfico. É autor dos romances Não há nada lá (2001), Do fundo do poço se vê a lua (Prêmio Machado de Assis da Fundação Biblioteca Nacional, 2010), A tristeza extraordinária do leopardo-dasneves (2013), Noite dentro da noite (2017) e A morte e o meteoro (2019). Também publicou a novela Hotel Hell (2003) e os volumes de contos Sonho interrompido por guilhotina (2006) e Curva de rio sujo (2007), além dos poemas de Animal anônimo (2002) e O sonâmbulo canta no topo do edifício em chamas (2018). Nascido em Cuiabá, hoje vive em São Paulo.

P.: Em entrevista ao jornal Correio Braziliense, você aponta para a dificuldade de escrever distopias no Brasil, uma vez que "a própria realidade brasileira é distópica". No entanto, ainda que não seja exatamente uma distopia, A morte e o meteoro não deixa de estabelecer um diálogo com esse gênero, e, na mesma entrevista, você declara que o livro foi escrito "em estado de extrema urgência". Apesar de toda a dificuldade, é urgente escrever uma distopia brasileira? Que características ela teria? De que forma ela seria diferente das distopias produzidas fora do país?

R.: A "extrema urgência" a que me referi na entrevista citada não tinha a ver com uma necessidade de fabricar um texto que atendesse a essa ou àquela tendência ou gênero, nada disso. Era uma urgência existencial, íntima, motivada pelos rumos sociopolíticos do país. Não consigo pensar em meus livros como pertencentes a uma determinada tradição ou escola ou o que seja, ao menos não enquanto os escrevo. Escrever um romance é como dirigir um automóvel desgovernado, e 
qualquer tentativa de pisar no freio - por exemplo, determinar que "ah, este vai ser uma distopia" - colocaria tudo a perder. Ao menos é como funciona comigo. Evidentemente, quando o livro começa a ser lido e o colocam sob este ou aquele guardachuva, eu paro e penso: nossa, escrevi uma distopia. De todo modo, não me atrai em nada ver meu trabalho circunscrito ao gênero, pois essa é uma bela maneira de enquadrar autores que, de outro modo, poderiam ser lidos de maneira mais livre e universal. Penso no uruguaio Mario Levrero, por exemplo, que inicialmente teve seus primeiros contos publicados em revistas de ficção científica e depois levou anos para se livrar desse estigma. Quanto à distopia brasileira, o problema que se impõe é o de que nossa sociedade nunca se desenvolveu suficientemente para sofrer a decadência ou recesso típicos da distopia. Somos desgraçadamente distópicos desde o início, ou ao menos desde que o primeiro português assentou suas tamancas nestas praias.

P.: Ainda em relação à pergunta anterior, muitos dos elementos propriamente distópicos da narrativa, como o colapso da floresta amazônica e o papel que o Estado brasileiro teria desempenhado nesse processo, são mencionados quase de passagem, ao mesmo tempo em que desempenham um papel central na narrativa. Na verdade, os contornos do Estado permanecem indefinidos em A morte e o meteoro, quase como se ele tivesse uma presença fantasmagórica, mas de fortes efeitos negativos. A que se deve esse ocultamento?

R.: Sigo aquele pensamento benjaminiano de que uma boa narrativa não deve explicar nada, ou quase nada. E pensando 
bem, caso você conheça as margens deste país, onde não há presença nenhuma do Estado e tudo está largado ao deus-dará, o Estado só pode ser representado de maneira espectral. Assim, eu pretendia escrever um romance ou uma novela-relâmpago, movida a eletricidade. Não convinha detalhar aspectos que teriam importância apenas passageira no substrato do relato.

P.: Como ocorre em muitos de seus outros romances, há uma forte presença da realidade histórica brasileira, ou mesmo latino-americana, em A morte e o meteoro. Entretanto, se há passagens mais estritamente realistas no romance, como quando Boaventura relata sua convivência com a índia kaajapukugi numa cidadezinha amazônica, o relato é constantemente perpassado por elementos de outros gêneros, como o fantástico, o gótico e a ficção científica. Como você vê a relação entre o realismo e esses elementos insólitos em sua obra? O realismo não dá conta da realidade?

R.: O realismo é essa alucinação que se interpõe entre nós e a realidade, como dizia Macedônio Fernández. Como convenção, é limitador. Procuro fazer uma ficção imaginativa, então, para que os voos sejam possíveis, o solo precisa ser bem sólido. Ou seja, para manter a verossimilhança, a construção ficcional precisa ser bem arquitetada, só a partir daí o insólito se torna crível. Basicamente, o extraordinário sai do ordinário, do comum. Do familiar, como já havia apontado o Dr. Sigmund.

P.: Pode-se dizer que há vários deslocamentos na narrativa de A morte e o meteoro - o deslocamento dos índios kaajapukugi da Amazônia para o México, dos astronautas chineses para 
Marte, de Boaventura em sua viagem pelo rio, e mesmo - deslocamento entre vários gêneros literários. Qual é a importância do deslocamento em sua obra? Ele aponta para uma falta de pertencimento ou para o estabelecimento de novas relações?

R.: Creio que a uma falta de pertencimento, a uma impossibilidade de voltar para casa. Na medida em que se perde o mundo de onde se saiu, só nos resta inventar outro. A literatura que produzo é bastante deslocada da tradição brasileira, talvez por explorar um sentido de brasilidade alienígena, fora do eixo. A ideia é colonizar uma parcela de imaginário - composta pelo Mato Grosso, o Centro Oeste - e torná-la só minha.

P.: $O$ retorno do passado é uma constante em $A$ morte $e$ meteoro. Boa parte do romance gira em torno do relato de Boaventura sobre sua experiência no passado com os kaajapukugi e da questão da origem desse povo, sem falar da "psicose colonial nas Américas" que assombra a narrativa desde suas primeiras linhas. No entanto, a relação com 0 passado é tensa: ao mesmo tempo em que ele insiste em ressurgir, há várias tentativas de apagá-lo, como quando - narrador destrói a casa dos pais num incêndio. Além disso, descobre-se, no final do romance, que a origem dos kaajapukugi está relacionada aos astronautas chineses que, no presente da narrativa, acabam de partir para Marte. Assim, de certo modo, o futuro se transforma no passado. De que forma, na sua opinião, o passado se imbrica com o presente, ou o presente molda o passado? Qual a relação entre memória pessoal e a memória histórica coletiva? 
R.: Gosto daquele ditado russo que afirma que "o passado é imprevisível", assim como de Brecht reescrevendo Sófocles ("Antígona"): "o passado abandonado jamais se torna passado". Creio que o coletivo atende aos mesmos princípios reativos do pessoal: se não curamos o passado, ele sempre permanecerá presente.

P.: Há ainda outro tipo de retorno do passado em $\mathbf{A}$ morte e o meteoro, o de narrativas ou obras culturais anteriores - há fortes ecos de Coração das trevas, de Joseph Conrad, ou de sua adaptação para o cinema em Apocalypse Now, na viagem de Boaventura rio acima na Amazônia. Há uma tradição distópica/colonial/apocalíptica com que você dialoga? De que forma ela influencia o seu trabalho? Até que ponto nossa percepção do presente é influenciada por essas narrativas?

R.: Coração das trevas e o conto "An outpost of progress", do Conrad, foram importantes para a concepção de meu livro, que se propõe a um diálogo com ambos. A maneira com que o autor tratou a tragédia colonial no Congo fala diretamente ao modo com que enxergo o processo colonial brasileiro, genocida, racista, extrativista e ainda em vigor, infelizmente, pois o Estado brasileiro (e o governo que aí está desde 2019) não passa de mais um capítulo na exploração deste território a despeito de quem o habita.

P.: Muitas das ambientações do romance, como a floresta que Boaventura atravessa para chegar à aldeia dos kaajapukugi ou a ilha sagrada dos índios, com seus besouros que se alimentam de sangue, são sombrios ou monstruosos. Além 
disso, esses lugares parecem concentrar um forte conteúdo simbólico. Existe aí um diálogo com elementos de narrativas oriundas da cultura de massa sobre o encontro colonial? Por que esses lugares, que em princípio ofereceriam um contraponto à civilização ocidental, acabam se tornando também ambientes de horror?

R.: Não sei, mas tendo a enxergar a natureza de forma opressiva, o que ela realmente é. A selva é o lugar onde nos tornamos comida, daí essa perspectiva. Colombo, ao chegar à América, acreditou que havia descoberto o Paraíso cristão, e foi efetivamente tomado por uma glória qualquer, uma alucinação, acreditando que cumpria um papel incontornável na epopeia bíblica. Fico imaginando o que ele pensou quando foi picado pelo primeiro borrachudo em terra firme, se essas conviç̧ões não foram abaladas.

P.: A morte e o meteoro termina num quadro que é como o final de 0 Guarani ao avesso: o narrador e filho mestiço de Boaventura sozinhos num avião sem rumo que sobrevoa um mar de fogo, como Peri e Ceci flutuando no topo da palmeira durante a enchente do Paquequer. A sua narrativa sobre o fim dialoga com nossas narrativas ficcionais sobre a origem? Esse diálogo se faz necessário hoje?

R.: Creio que sim. Mas percebo certo otimismo no final de "A morte e o meteoro", a possibilidade de que tudo recomece. No entanto, a impossibilidade de se fazer tudo diferente, e de apenas reproduzir tudo de errado que a humanidade fez, é uma condenação. 
P.: Como apontado acima, $\mathbf{A}$ morte e o meteoro incorpora diversos elementos da ficção não realista, como o fantástico e a ficção científica, principalmente naqueles momentos do romance relacionados a seu componente apocalíptico. Falar sobre o fim estimula, de alguma maneira, a liberdade imaginativa?

R.: Conforme os anos passam e novos livros chegam, percebo que não tenho outro tema a não ser o apocalipse. Meu primeiro romance tratava do apocalipse a partir do fim dos livros, considerando que, se o universo está contido em um livro, acaba o livro, acaba o universo. E agora veio esse meteoro fatal. Devo estar tomado por uma obsessão mórbida, assim como aqueles sectários assassinos dos séculos $\mathrm{XI}$ ao $\mathrm{XVI}$ relatados pelo Norman Cohn no ensaio "Cosmos, Caos e o Mundo que Virá", todos inspirados pela simbologia do Livro do Apocalipse. Não sou diferente deles, no entanto acho que o fim não será festivo e iluminado com fogos de artifício como um réveillon. Acho que o fim será cinzento, quente e longuíssimo, e talvez já esteja acontecendo. Meus livros apenas querem incutir isso nos leitores, dizendo "ei, parece que já começou, e agora?"

P.: A morte e o meteoro é um romance apocalíptico e, portanto, marcado por várias perdas: a perda de todo um ecossistema, de toda uma etnia e, finalmente, de todo um mundo. Além disso, tanto o narrador quanto Boaventura são marcados pelo trauma da perda de seus pais, que pode ser considerada o ponto de partida de suas trajetórias no romance. Até que ponto somos definidos por nossas perdas? Há esperança frente ao apocalipse? 
R.: Como disse, não temos mais futuro nem esperança. Agora precisamos decidir se vamos continuar a aproveitar a festa até a última luz se apagar ou se antecipamos o fim da festa. O Doomsday Clock de 2020 diz que faltam só cem segundos para a meia-noite. 